\title{
WACANA LOKAL DALAM PENDIDIKAN SURAU STUDI FILOLOGIS TERHADAP NASKAH MANTIQ
}

\author{
Oleh: Yusri Akhimuddin*
}

\begin{abstract}
The problem of this research was what and how local discourse found in the script of mantiq as instructional material in traditional informal Islamic educational institution (surau). The method employed was basic method by referring to philological steps. The findings showed that: first, the way the Arabic letters were written did not show similarity to that of one of standard Arabic fonts among the Arabic speaking people. Second, there were meanings of vocabulary below the texts written in Minangkabaunese dialect using Malay-Arabic letters. The materials for mantiq, nabwu, and balaghah were found in single script (text). As the instructional materials, such three components support the competency for fluent speaking, appropriate logic and aesthetic choice of language as applied in pasambahan
\end{abstract}

Kata Kunci: wacana lokal, naskah mantiq, pendidikan surau.

\section{PENDAHULUAN}

$\mathrm{D}$ i Minangkabau, salah satu tempat aktivitas pendidikan dilakukan di surau. Surau adalah bangunan yang memiliki multifungsi, selain tempat ibadah juga berfungsi sebagai interaksi sosial dan pendidikan. Karena itu setiap suku di Minangkabau mempunyai surau kaum, dan setiap nagari mempunyai satu surau nagari (wilayah pemerintahan terkecil di Sumatera Barat). Jadi dalam satu nagari terdapat satu surau nagari dan beberapa surau kaum. Menurut Yusuf dalam Zuriati (2004: 104) bahwa surau baik di wilayah luhak maupun di rantau (sebut-an untuk wilayah Minangkabau bagian pesisir) adalah salah satu tempat penulisan naskah di Minangkabau.

Naskah sangat penting untuk pembangunan bangsa dalam upaya memelihara, membina dan mengembangkan kebudayaan, baik kesenambungannya mau- pun untuk menguatkan kepribadiannya. Kandungan isi naskah dari masa lampau itu sangat penting, terlebih dalam menghadapi masa globalisasi dengan teknologi yang serba canggih (Tjandrasasmita, 2006:2).

Digitalisasi naskah oleh Tim Digitalisasi Naskah Fakultas Sastra Universitas Andalas Padang (2008), didanai oleh British Library, menemukan bahwa salah satu tempat penulisan dan penyalinan naskah di Minangkabau mayoritas dilakukan di surau-surau tarekat. Seperti surau Bintungan Tinggi, surau Lubuk Ipuh, dan surau Ampalu Tinggi di Pariaman. Surau Gadang Pariangan dan surau Malalo di Batusangkar (tarekat Satariyah). Surau Tanjung di Batang Kapeh Painan, surau Batu Hampa di Payakumbuh (tarekat Naqsabandiyah).

Dari 250 manuskrip yang ditemukan di surau-surau, berisi tentang agama Islam, adat, obat-obatan, ramalan, azi-

* Penulis adalah Lektor dalam Mata Kuliah Bahasa Arab pada STAIN Batusangkar 
mat, dan lain-lain. Naskah-naskah keagamaan seperti naskah alquran, tafsir, hadist, ushul al fiqh, fiqh, nahwu sharaf, tasawuf, balaghah, dan mantiq.

Penelusuran manuskrip ini, menggambarkan kondisi alam Minangkabau ketika naskah itu disalin atau ditulis, yaitu menyatunya antara teori dan praktek dari Adat Basandi Syarak, Syarak Basandi Ktabullah (ABS-SBK). Tergambar betapa eratnya kaitan adat dan agama di Minangkabau. Karena setiap surau yang memiliki naskah, ditemukan di surau tersebut naskah adat dan naskah agama. Dalam naskah keislaman digunakan istilah-istilah adat, demikian juga pada naskah adat ditemukan istilahistilah Islam.

Surau telah mengisi kekosongan lembaga pendidikan di Minangkabau. Surau sebagai institusi pertama kali dilakukan oleh Syekh Burhanuddin, putra Pariangan Tanah Datar yang mendirikan surau di Tanjung Medan Ulakan Pariaman. Dalam sejarah, banyak tokohtokoh Minangkabau yang lahir dari proses pendidikan surau, seperti Ahmad Khatib al Minangkabauwi, Syekh Sulaiman Arrasuli (Candung), Syekh Djamil Djambek (Bukittinggi), Syekh Djamil Djaho (Padang Panjang), dan Syekh Thaib Umar (Sungayang). Pendidikan surau telah memberi bekal generasi Minangkabau untuk menempuh kehidupan agar menjadi manusia yang kamil (sempurna) baik di kampung halaman dan di rantau.

Berbeda dengan kondisi Minangkabau sekarang 'krisis pemimpin yang ulama dan ulama yang pemimpin'. Untuk itu Pemerintah aerah Sumatera Barat mencanangkan "Program Kembali ke Surau dan Kembali ke Nagari". Dengan harapan akan lahir generasi Minangkabau seperti Ahmad Khatib, Nastir, Hatta, Hamka dan tokoh-tokoh lainnya. Namun program 'Kembali Ke Surau dan Kembali Ke Nagari' belum mencapai apa yang diinginkan. Surau kosong dari substansinya sebagai lembaga pendidikan dan lembaga sosial.

Helmi (2006: 2) menyatakan bahwa sistem pendidikan surau mempunyai empat ciri utama; yaitu: scholarly tradition (penguasaan materi yang mendalam), artikulasi terbagun baik lisan dan tulisan, pemahaman terhadap nilainilai dasar kehidupan seperti adat dan agama, dan social and private enterpreneurship (kemampuan menciptakan kekayaan untuk pribadi dan sosial).

Penguasaan materi yang mendalam sesuai dengan ungkapan mambilang dari aso, mangaji dari alif (membilang dari satu, dari mengaji dari alif). Terbangunnya artikulasi lisan dan tulisan dengan baik menghasilkan out put surau yang mampu berpikir, berbicara dan menulis dengan baik dan benar. Pemahaman yang mendalam tentang adat sesuai dengan ungkapan hadist badalia kato bamisa, alam takambag jadi guru (kalau bicara tentang agama ada dalilnya, bicara tentang sesuatu ada contohnya, alam yang luas adalah dijadikan sumber pengetahuan). Kemampuan menciptakan kekayaan sesuai dengan ungkapan anak dipangku kamanakan dibimbiang urang kampuang dipatenggangkan.

Terbangunnya cara berpikir dan berbicara yang baik tentu tidak lepas dari materi ajar yang diberikan, diantaranya ilmu bahasa seperti balaghah, nahwu sharf, dan ilmu mantiq. Pembahasan di sini lebih difokuskan kepada ilmu mantiq, namun bukan berarti dua ilmu lainnya sama sekali diabaikan. Husein Al-Kaff (2000: 1) mendefinisikan Ilmu mantiq adalah ilmu yang membahas tentang alat dan formula berpikir. Sehingga seseorang yang menggunakannya akan selamat dari cara berpikir yang salah. Kemampuan berpikir, berbicara, dan menulis dari 'alumni surau' telah melahirkan tokoh-tokoh Minangkabau tingkat daerah, nasional, dan internasional. 
Salah satu bukti bahwa Ilmu mantiq adalah sebagai materi ajar di lembaga surau, dapat dibuktikan dengan ditemukannya manuskrip yang berisi tentang ilmu mantiq di surau-surau Minangkabau. Dengan diajarkannya ilmu mantiq di surau-surau, yang pada awalnya disampaikan secara lisan, kemudian dilanjutkan dengan penyalinan oleh murid-murid. Murid-murid yang sudah tamat membawa naskah salinannya ke kampungnya, atau ke lokasi baru untuk mendirikan surau yang baru sesuai dengan petunjuk guru yang salah satunya adalah surau Lubuk Ipuh nagari Kurai Taji, kecamatan Nan Sabaris, kabupaten Padang Pariaman, Sumatera Barat. Apa kandungan isi dan bagaimana wacana lokal dalam naskah mantiq sebagai materi ajar di lembaga surau suatu hal yang menarik untuk dikaji. Diharapakan tulisan ini dapat mendeskripsikan isi naskah mantiq serta menjelaskan wacana lokal dalam naskah mantiq sebagai materi ajar.

\section{PEMBAHASAN}

Dalam filologi, kata naskah adalah yang menyangkut dengan bentuk fisik dari karya tulisan tangan zaman lampau yang merupakan objek kajian kodikologi, sedangkan yang menyangkut ide dan kandungan isinya dikaji dengan ilmu tekstologi. Tekstologi naskah mantiq dalam penelitian ini merupakan kajian konten yang dihubungkan dengan wacana lokal di mana naskah ini disalin.

Di Minangkabau, surau adalah salah satu wahana pendidikan dan interaksi sosial masyarakat. Di surau dipelajari ilmu agama, adat, dan pencak silat. Ketiga bidang ilmu tersebut saling terkait satu sama lain. Misalnya dalam membangun artikulasi yang baik, dipelajari ilmu mantiq bidang agama, petatah petitih dalam bidang adat, dan ilmu pencak (gerak) dan ilmu silat (silat lidah) dalam pencak silat. Selain tempat ibadah, dan mengaji, surau juga sebagai tempat bermalamnya laki-laki Minang, duda, dan para musafir. Substansi surau di Minangkabau merupakan sebuah lembaga pendidikan bagi masyarakat Minangkabau yang menyelaraskan keterpaduan antara adat dan agama. Maka dalam memberikan penjelasan dalam suatu pelajaran guru sering memberikan perumpamaan yang dekat dengan kehidupan sehari-hari. Keselarasan ini diungkapkan dengan hadis badalia kato bamisa, alam takambang jadi guru. Naskah mantiq surau Lubuk Ipuh tentu tidak luput dari kondisi seperti ini. Bahwa dalam naskah mantiq juga ditemukan penjelasan yang berkenaan dengan kultur budaya Minangkabau.

Dalam Seminar Sejarah dan Kebudayaan Minangkabau, tanggal 1-7 Agustus 1970 di Batusangkar, Hamka mengungkapkan, bahwa dalam Kaba Cindua Mato disebutkan juga keserasian antara adat dan agama di Minangkabau, yaitu dengan adanya Rajo Tigo Selo (Rajo Adat di Buo, Rajo Ibadat di Sumpua Kuduih, dan Rajo Alam di Pagaruyung) dalam mengatur tata kehidupan di Minangkabau (LKAAM, 2002: 169).

Mantiq adalah sebuah ilmu yang membahas tentang formula berpikir, sehingga seseorang yang menggunakannya akan selamat dari cara berpikir yang salah. Manusia sebagai makhluk yang berpikir tidak akan terlepas dari berpikir. Namun, pada saat berpikir, manusia seringkali dipengaruhi oleh berbagai tendensi, emosi, subyektivitas dan lainnya sehingga ia tidak dapat berpikir jernih, logis, dan obyektif. Mantiq merupakan upaya agar seseorang dapat berpikir dengan cara yang benar, tidak keliru (Kaff, 2000: 1, diakses dari: islam@isnet.org, tanggal 7 Maret 2008).

Ilmu mantiq disebut juga dengan ilmu logika, logika berasal dari bahasa Yunani (logos) yang berarti hasil pertimbangan akal pikiran yang diutarakan 
lewat kata dan dinyatakan dalam bahasa. Jadi ilmu logika mempelajari tentang kecakapan untuk berpikir secara lurus, tepat, dan teratur (diakses dari: http//id.wikipedia.org, tanggal 7 Maret 2008).

\section{Deskripsi Naskah Mantiq Surau Lubuk Ipuh Padang Pariaman}

Penulis: Al Faqir Ibn Muhammad, Pemilik: Tuanku Qadhi Lubuk Ipuh, Penanggalan: Selesai ditulis bulan Zulhijah hari Selasa waktu zuhur di Balad Kurai Taji, Tempat Penyalinan: Nagari Kurai Taji.

Ukuran naskah: 21 x 17; ukuran blok teks: 15 x 10,5; tiap kuras 12 lembar; jumlah kuras: 4 kuras; 96 hlm; 1120 baris per hlm; tanpa penomoran halaman; alas naskah dari kertas eropa; Watermark dan Countermarki: CONCORDIA/ VDL; ukuran tulisan: sedang; menggunakan garis tebal (Chain lines) dan garis tipis (laid lines); aksara dan bahasa: Arab; warna tinta: hitam untuk bagian isi dan merah untuk rubrikasi; garis-garis pengarah guide lines menggunakan benda setengah tajam; tanpa alihan (catchword); tanpa iluminasi dan ilustrasi, dan tanpa cap.

Keadaan naskah: Sampul dimakan serangga, tulisan jelas terbaca, halaman utuh pada jilidan kuras.

Naskah mantiq koleksi surau Lubuk Ipuh telah dikodifikasi oleh Tim Digitalisasi Naskah Minangkabau Fakultas Sasatra Unand Padang bernomor LBI 03. Naskah ini adalah salinan atau nuqilan dari naskah sebelumnya Syarhu Sullami al Munawwaraq fi Ilmi Mantiq yang disalin ulang oleh Pakiah Sidi Abu Bakar putra negeri Lubuk Ipuh Kurai Taji kabupaten Padang Pariaman ketika belajar agama di negeri Sumpur Malalo Kabupaten Tanah Datar.

Teks diawali dengan basmalah, selanjutnya dengan alhamdalah, salawat untuk Nabi Muhammad saw, para keluarga, dan sahabatnya. Teks ini ditulis adalah karena permintaan bagi para penuntut ilmu dengan tujuan dapat bermanfaat bagi para pemula agar terhindar dari kesalahan dalam memahami kitab dan sunah nabi. Isi pokok dari teks disajikan dengan bentuk bait syair, kemudian dilanjutkan penjelasannya dengan menggunakan struktur kalimat Arab (nahwu) dan gaya bahasa Arab (balghah). Dua ilmu tersebut dipakai dalam menjelaskan kandungan teks (ilmu Mantiq).

Deskripsi naskah ilmu mantiq dalam bait pertama menyatakan pengertian dari ilmu mantiq yaitu ilmu yang memelihara lidah dari kesalahan berpikir agar sampai kepada pemahaman yang benar dan sempurna. Ilmu mantiq adalah alat yang akan menghapus kebodohan agar sampai kepada ilmu pengetahuan.

Bait selanjutnya menyatakan alasan pemilihan nama teks dengan sullami al munawwaraq. Pemilihan nama itu didasarkan karena tangga akan bernama tangga kalau anak tangganya tersusun dengan baik. Selain itu juga dilihat dari fungsi tangga, yaitu untuk mencapai kepada sesuatu yang tinggi, sehingga dengan ilmu mantiqlah bisa menyampaikan kita kepada pemahaman makna yang tinggi.

Jawazul al istighal adalah bagian ilmu mantiq yang lebih dahulu diterangkan. Diterangkan pula perbedaan ulama dalam hal bolehnya istighal untuk memperoleh petunjuk dari al quran dan sunah. Ibnu Sholeh dan Nawawi tidak setuju dengan bolehnya istighal, sedangkan Ghazali dan pengikutnya cenderung membolehkan istighal dalam memahami kitab dan sunnah.

Selanjutnya diterangkan tentang ilmu pengetahuan, proses pemerolehannya, jenis-jenisnya berdasarkan penangkapan indrawi atau pemahaman terhadap rangsangan dari alam semseta. Disebutkan konsep, deskripsi, ilmu, dan kebenaran realita. 
Ada ilmu yang bersifat dharury dan ada juga yang iktisabi, yaitu ilmu yang diperoleh tanpa proses pembelajaran sedangkan ilmu iktsabi diperoleh dengan proses usaha pembelajaran terlebih dahulu.

Dalam memhami makna sesuatu diperlukan ilmu dalalah, ilmu ini membekali orang yang belajar mantiq untuk bisa sampai pada makna yang mendalam dan detail dari suatu pembicaraan. Ilmu ini berkenaan dengan hubungan perkataan dengan referensi atau tuturan dengan rujukannya. Dalalah dibagi atas dalalah muthabaqah yaitu kesesuaian penunjuk dengan yang ditunjuk, dan dalalah tadhamun adalah kesesuaian penunjuk dengan bagian yang ditunjuk beradasarkan logika.

Kebenaran logika dan keteraturan dalam berpikir menjadikan bahasa yang diucapakan kepada communincant akan mudah dicerna, sederhana, dan memiliki makna yang dalam.

Bahasan selanjutnya. mengenai kuliyat (generalization) dan juz'iyat (partikular), pengetahuan ini akan membekali para pelajar dengan metode berpikir dan menyimpulkan sesuatu dengan benar.

Sebenarnya bahasan ilmu mantiq sangat luas, tapi karena pembahasan penelitian dibatasi dengan wacana lokal yang ada pada makna kosa kata, maka penerjemahan teks juga dibatasi pada bagian teks yang memiliki arti kata dalam bahasa lokal.

\section{Wacana Lokal dalam Naskah Mantiq}

Ada beberapa alasan kenapa naskah LBI 03 memiliki wacana lokal. Pertama, naskah LBI 03 disalin di Minangkabau dan oleh orang Minangkabau tetapi tetap menggunakan aksara Arab. Cara penulisan aksara Arab dalam kalimat tidak menunjukkan persamaan dengan salah satu gaya penulisan khat Arab yang baku bagi kalangan Arab. Penyalin menggunakan gaya penulisan tersendiri, sehingga ada beberapa huruf yang agak mirip secara sepintas kelihatan sama bentuknya.

Kedua, terdapat arti kosa kata yang ada di bawah teks dalam bahasa Minangkabau beraksara Arab Melayu. Dalam hal ini, ketika mempelajari ilmu mantiq para murid anak siak menggunakan ungkapan yang dipakai dan disepakati pada masa itu oleh penutur bahasa tersebut. Misalnya baris ke 15 pada halaman 17 teks yang tertulis لا يمنع diartikan dengan منك menagahkan yang dalam bahasa Indonesia berarti melarang. Kata menagahkan berasal dari kata tagah, kata tagah dipakai untuk melarang atau mencegah dari suatu pekerjaan. Berikut salah satu pemakaian kata tagah dalam pantun Minangkabau:

ditarah indak tatarah

ditutuah makonyo lai

ditagah indak tatagah

disuruah makonyo lai

ditebas tidak tertebas

ditebas juga akhirnya

dilarang tidak terlarang

dusuruh juga pada akhirnya

Ketiga, Naskah LBI 03 adalah satu naskah yang mengandung tiga teks, dimana ketiga teks tersebut saling memperkuat satu dengan lainnya dalam pengajaran dan pembinaan artikulasi yang baik, yaitu teks nahwu, teks mantiq, dan teks balaghah. Ilmu nahwu menjaga penutur dari kesalahan dalam merangkai kata-kata menjadi kalimat yang baik dan benar. Ilmu mantiq menuntun cara berpikir yang logis dan sitematis, sehingga terhindar dari kesalahan berpikir dalam mengambil suatu kesimpulan. Selanjutnya, ilmu balaghah memberikan gaya tutur yang indah dalam menyampaikan ide-ide dan gagasan kepada lawan bicara.

Ketiga komponen ini sangat mendukung dalam materi ajar pada pendidikan surau, sehingga 'para alumni surau' mampu berbicara dengan bahasa 
yang fasih, logika yang benar, dan gaya bahasa yang enak dan indah. Kemampuan ini dapat dilihat dari kemahiran alumni surau dalam pasambahan. Ternyata materi ajar di pembinaan artikulasi di surau disesuaikan dengan kebutuhan yang ada di masyarakat. Hal ini sesuai dengan Ansyar (1989:54) yang menyatakan bahwa biasanya kurikulum disusun dan dikembangkan agar nilai-nilai yang dianut dapat dilaksanakan oleh anak didik.

Pasambahan adalah tuturan indah yang penuh makna yang disampaikan dalam berbagai kegiatan di Minangkabau. Pasambahan ada yang dilakukan dalam bentuk pidato, diantaranya seperti pidato pengangkatan penghulu, pidato kubur, dan pidato lainnya sesuai dengan tujuan dan suasana. Pasambahan dalam bentuk tanya jawab diantaranya seperti pasambahan menjeput marapulai (penganten pria), mempersilahkan memakan hidangan, dan pasambahan mohon pamitan. Penulis menggunakan katakata yang dipakai dalam pasambahan untuk menunjukan wacana lokal yang dipakai dalam naskah mantiq.

\section{Bahasa Lokal dan Materi Ajar}

Penjelasan teks pada pias tidak mengikuti salah satu gaya penulisan aksara Arab yang ada, seperti gaya tulisan nasakh dan tsulust atau gaya tulisan lainnya. Penyalin menggunakan gaya penulisan tersendiri dalam menuliskan penjelasan teks tersebut. Namun di sinilah letaknya genius lokal dalam naskah mantiq ini. Meskipun tulisan tidak sebaik dan serapi tulisan yang ada pada blok teks, misalnya huruuf nun, tzal, zai atau kaf dan lam ditulis hampir dalam bentuk yang sama, namun penjelasan ini tetap menggunakan gramatika bahasa Arab yang benar. Hal ini mencerminkan bahwa penulis juga menguasai gramatika bahasa Arab yang digunakannya dalam mempelajari ilmu mantiq. Inilah sebabnya kenapa kedua ilmu ini dan ilmu balaghah digabung dalam satu naskah dalam penjilidan kurasnya.

Ketiga ilmu alat tersebut, gramatika bahasa Arab, gaya bahasa, dan cara berpikir yang benar adalah materi ajar yang saling terkait dalam membekali anak didik di surau agar memeiliki kompetensi artikulasi yang sempurna.

Seseorang yang memiliki kemampuan gramatika bahasa yang baik dapat menyusun kata-kata menjadi kalimat yang efektif. Susunan kalimat yang efektif akan membentuk paragraf yang saling terkait. Kemampuan gramatika yang baik kalau tidak didukung oleh gaya bahasa yang baik dan pemilihan kata yang benar juga akan terasa hampa dan tidak memberikan makna, sehingga terasa membosankan saat dibaca atau didengar. Untuk itu kemampuan balaghah sebagai stylistik bahasa perlu diberikan kepada anak didik di surau. Kemampuan tersbut didukung dengan pengalaman belajar dalam pasambahan. Ilmu mantiq adalah 'otak' dari kemampuan artikulasi yang diberikan di surau. Kedua ilmu yang awal, nahwu dan balaghah tidak akan berfungsi kalau cara berpikirnya tidak benar.

Arti kata bahasa Arab dalam teks naskah ditulis dalam aksara Arab Melayu, namun berbahasa Minangkabau dapat diiventarisir dengan menunjukkan tempatnya menurut halaman dan baris naskah mantiq yang disajikan dalam table 1. Dalam penyajian ini, penulis tidak bisa menggabungkan aksara nun, jim, ngain yang pakai titik tiga dalam aksara Arab Melayu untuk mewakili bunyi (ny, c, dan ng), demikian juga huruf kaf titik satu sebagai ganti huruf (g) dalam bahasa Indonesia. Misalnya kata kebesarannya hanya ditulis kata cerdik ditulis , kata yang ditulis يع kata segala ditulis . 
Tabel: 1

\begin{tabular}{|c|c|c|c|c|c|}
\hline HIm & Brs & Bahasa Teks & Bahasa Lokal & $\begin{array}{c}\text { Arti Kata dalam } \\
\text { bahasa Minangkabau }\end{array}$ & $\begin{array}{c}\text { Arti kata dalam bahasa } \\
\text { Indonesia }\end{array}$ \\
\hline \multirow[t]{3}{*}{2} & 11 & بحده | la & كبسرنن & kebesarannya & kemulaiaan \\
\hline & 14 & زكى & 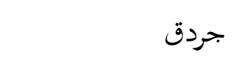 & cerdik & cerdas, pintar \\
\hline & 16 & اللسلم المنورق & تغك يغ برتته & tangga yang bertatah & tangga yang tersusun \\
\hline \multirow[t]{2}{*}{3} & 9 & نتائج & انق كج & anak kaji & hasil \\
\hline & 14 & محللا & تمفت اى بالكلام & tempat ia berkalam & tempat dia berbicara \\
\hline \multirow[t]{3}{*}{5} & 2 & سديد & بتول2 & betul-betul & sangat,sungguh \\
\hline & 10 & 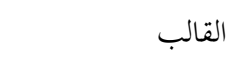 & لمباك ل & limbak & balik, lawan \\
\hline & 14 & 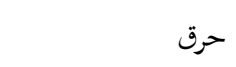 & منجرقكن & menjarakkan & membakar \\
\hline 6 & 5 & الخدر & كلمب & kelambu & \\
\hline \multirow{3}{*}{$\begin{array}{l}10 \\
12\end{array}$} & 6 & دقيق & سهالس2 & sehalus-halusnya & rinci \\
\hline & 15 & ينبئ & كمرتاه & memeritahu & mengabarkan \\
\hline & 17 & برسم & درسمكن & dirasamkan & deskripsi \\
\hline \multirow[t]{2}{*}{17} & 12 & & تساد ت تاكه & tiada tertakah & tidak terbayang \\
\hline & 15 & يمنع & منكهكن & menagahkan & melarang \\
\hline
\end{tabular}

Kata Kabasaran, di antara pepatah Minangkabau yang menggunakan kata kabasaran adalah untuk menyatakan keagungan Tuhan dalam penciptaan langit dan bumi sebagaimana petikan berikut:

Dan telah dijadikannyo langit jo bumi, alam sarato isinyo Ampek parhiasan di langit, ampek pulo kabasaran di bumi.

Mano nan ampek perhiasan di langit aso matohari, kaduo bulan, katigo bintang, kaampek timur Mano nan ampek kabasaran di bumi Aso makah, kaduo madinah, katigo baitu maqdis, kaampek baitul hajarat

Dan telah dijadikan langit dan bumi, alam beserta isinya

Empat perhiasan di langit, empat pula kebesaran di bumi

Mana yang empat perhiasan di langit pertama matahari, kedua bulan, ketiga bintang, keempat timur

mana yang empat kebesaran di di bumi:

pertama Makah, kedua Madinah, ketiga Bitul Maqdis, keempat Baitul Hajarat.

Dalam bait pasambahan tersebut digunakan kata kabasaran untuk memaknai kata dalam bahasa teks. Pemilihan kata ini menunjukan kemahaagungan Tuhan dari seluruh alam. Gambaran keagungan Tuhan ini diperlihatkan melalui berbagai penciptaannya di langit dan di bumi yang semuanya adalah gambaran kebesaran Tuhan. Dalam bait pasambahan ini, terdapat hubungan antara adat dan agama Islam di Minangkabau, di mana alam dijadikan guru dalam mengenal Tuhan.

kalauk paku kacang balimbiang tampuruang lenggang lenggokkan 
silodang jadikan kayu

anak dipangku kemenakan dibimbiang

urang kampuang dipatenggangkan

alam takambang jadikan guru

Kata cerdik di Minangkabau dapat ditemukan dalam tuturan pasambahan berikut:

\section{Mangkonyo manyambah ambo di hadapan tuanku jo panghulu Ninik mamak nan gadang basa batuah \\ Nan cadiak tahu jo pandai Cadiak buliah bakeh batanyo Pandai nan buliah bakeh baraja Tau nan buliah bakeh baiyo \\ Makanya saya menyembah di hadapan tuan dan penghulu Ninik mamak yang besar dan bertuah \\ Yang cerdik tahu dan pandai Cerdik bisa tempat bertanya Pandai yang bisa tempat belajar Tahu yang bisa tempat beriya}

Kata cerdik, dalam bahasa Minangkabau diucapkan dengan cadiak. Cerdik bisa sebagai tempat minta pendapat atau solusi dari suatu permasalahan. Adapun kata pandai dipakai untuk orang yang banyak pengetahuan sehingga bisa sebagai tempat belajar.

Kata tatah dalam pengertian bahasa Minangkabau yang terdapat dalam pasambahan berati berukir atau berhias dan bersusun:

\section{Jikok dikaji jalan karano dunia namonyo \\ Almalu wal banuna zinata hayati dunia \\ Anak dan cucu, rumah gadang, lumbuang bapereng \\ Sananlah puyu batatah ameh \\ Bamusajik managah koto}

Kalau dibahas jalan karena dunia namanya

Almalu wal banuna zinata hayati dunia
Keturunan, rumah dan

perbendaharaan

Disitulah puyu berhias emas

Memiliki masjid di tengah kampung

Hal ini disampaikan ketika membandingkan apa sebenarnya kehidupan dunia ini. Kata puyu batatah ameh dipakai untuk menyatakan perhiasan dunia. Dalam bait pasambahan yang lain disebutkan sebagai berikut:

Rumah gadang, atoknyo ijuak batatah timah

Hinggok saga labah maraok

Gonjongnyo rabuang mambacuik

Antiang-antiang disamba burung

Kata tatah di sini berarti bersusun ijuk, mendeskripsikan keindahan bagian atap rumah gadang orang Minangkabau. Pemilihan kata tatah pada jenjang yang bertatah dalam mengartikan berfungsi untuk menjelaskan indahnya rangkaian kata yang diungkapkan dari proses cara berpikir yang tersusun atau yang sistematis.

Kata kalam dalam bahasa Arab berarti perkataan atau tuturan namun dalam pasambahan kata kalam, selain berarti bertutur bisa juga berarti tinta atau pena. Kata kalam dapat dilihat dalam pasambahan yang menyatakan terjadinya kebesaran penghulu mulai negeri akan dibuka dan ditunggui.

sajak samulo bumi kaditunggu

tatkalo nagari kadilaco

manusia mulai bakambangan

disinanlah janji nan diukua

buek nan dikarang

kok janji kaditapati

tasabuik dek adaik kadipatuhi

itu banamo garisan adat

kalam taceheng jadi ukia

kato sapatah jadi undang

disinan panghulu badiri

sejak mula bumi akan ditunggu

ketika negeri akan digarap

manusia mulai berkembang

disitulah janji diukur 
kesepakatn yang disetujui janji yang ditepati tertuang dalam adat yang dipatuhi itulah nama garisan adat kalam yang terlewat jadi ukiran kata sepatah jadi aturan di sanalah penghulu berdiri

Pasambahan tersebut menggambarkan kebijaksanaan seorang pimpinan kaum di Minangkabau. Sehingga dengan kebijaksanaan dan kesempurnaan pribadinya, sepatah kata saja dari seorang penghulu bisa jadi aturan. Seandainya ada kata yang taceheng di luar alurnya, bagi seorang penghulu kata tersebut dianggap sebagai hiasan tuturannya. Kata ini biasa dipakai oleh pemahat rumah gadang ketika membuat ukiran rumah gadang, sehingga ada garis yang terlewat, garis tersebut pun bisa menambah indahnya ukiran.

Kata limbak dipilih untuk menerjemahkan kata 'qalib' yang dalam arti harfiahnya adalah sebaliknya, atau yang membalikkan. Pembaca memilih kata limbak adalah berdasarkan makna yang sesuai dengan kontek dimana naskah itu dibaca.

Di Minangkabau, kata limbak berarti lebih, nan lain, selain dari itu, yang lebih dari itu. Biasanya kata limbak dipakai untuk menyatakan sesuatu yang butuh rincian atau pendiskripsian. Misalnya ketika kita ingin mempersilahkan para jamuan untuk makan, secara sederhana komunikator dalam pasambahan cukup mengatakan:

\section{Karena hidangan sudah ka tangah \\ Nasi minta dimakan \\ Aie minta diminum \\ Karena hidangan sudah terhidang \\ Nasi agar dimakan \\ Air supaya diminum}

Namun kalau kita ingin mendeskripikan seluruh apa yang kita hidingkan maka setelah tuturan di atas dilanjutkan dengan kata limbak. Maka tuturan selanjutnya adalah:

Limbak nan dari pado itu

Di alur nasi nan ka tangah

Kok dikaji asa mulonyo

Padi si ranak rimbun tulang

Tumbuah di lereng tanpa rotan

Dijamua dek puti linduang bulan

Hari paneh jamua dilingkuik-likuik

Hari hujan jamua dikaka-kaka

Lebih dari pada itu

Mengenai nasi yang terhidang

Jika ditelusuri asal muasalnya

Padi dari rimbun tulang

Tumbuh di lereng tanpa rotan

Dijemur oleh putri lindung bulan

Hari panas jemuran dilingkup

Hari hujan jemuran disebar

Selain dalam pasambahan kata limbak juga dipakai untuk penamaan suatu nageri yang bernama Batu Limbak. Negeri ini terdapat di tepi danau Singkarak kabupaten Tanah Datar. Dahulunya di daerah Simawang bagian perbukitan sekitar danau Singkarak terdapat telaga-telaga kecil yang banyak bebatuan. Suatu ketika batu yang berlebih itu jatuh mengelinding dan berhenti di tepi danau Singkarak, sehingga daerah tempat berhenti batu itu sampai sekarang bernama Batu Limbak, artinya batu yang berlebih.

Kaitan pemakaian kata limbak dalam teks sesuai dengan konteks teks saat dipelajari. Pengertian limbak yang berarti butuhnya penjelasan sesuatu dengan rinci mengarah pada kata yang ada di pasambahan dibanding asal-usul nama negeri Batu Limbak.

Berkaitan dengan kata 'qalib' dalam kalimat:

...dan demikian juga sesungguhnya arwah di alam malaikat dan badan dari alam milkiyah maka diletakan alam ruhaniyah di balik jasmaniy untuk menyempurnakan janji ketuhanan... 
Kalau digantikan kata balik dengan kata limbak, maka secara budaya orang Minangkabau tepat sekali bahwa di balik yang nampak terdapat beberapa hal yang perlu untuk dijelaskan sebagimana nasi yang nampak juga masih bisa dikaji asal muasalnya. Demikian halnya antara alam nyata dengan alam ghaib, seperti ruh yang ada dibalik jasmani.

Pada halaman 17 baris ke 12 terdapat kata tiada tertakah untuk mengartikan kata tidak tergambarkan atau tidak terbayangkan. Kata takah dalam bahasa Minang biasa dipakai untuk memberikan misal atau contoh sesuatu, sama maknanya dengan kata bak atau bagai. Takah bangau di tangah sawah seperti bangau di tengah sawah. Ungkapan ini diucapkan untuk menggambarkan seseorang yang tidak konsisten dan tidak cekatan.

Pada halam 17 baris ke 15 kata يمنع diartikan dengan منك menagahkan.. Kata menagahkan berasal dari kata tagah yang biasanya dipakai untuk melarang atau mencegah dari suatu pekerjaan.

\section{mangarojokan suruah, maantikan tagah}

Mengerjakan suruhan, menghentikan larangan

\section{PENUTUP}

Naskah mantiq berisi tentang pengertian dan fungsi ilmu mantiq, yaitu ilmu yang mengajarkan metode berpikir yang benar, mulai dari pemerolehan pengetahuan, menyimpulkan dan mengungkapkan pemikiran dengan baik dan benar. Teks mantiq juga berisi tentang konsep, deskripsi, realita, dan lain-lain seperti ragam dan kedalaman makna yang dikandung oleh lafaz menurut gaya dan sistematika penuturannya.

Wacana lokal dalam naskah LBI 03 dapat dilihat dari aspek aksara dan bahasa teks dan pada makna teks, serta jumlah teks yang dikandung dalam satu naskah. Aksara dan bahasa teks adalah aksara dan bahasa Arab yang tidak menurut kaedah salah satu gaya khat yang baku. Penyalin menggunakan gaya huruf tersendiri, sehingga huruf-huruf yang mirip terkadang ditulis dalam bentuk yang hampir tiada beda. Hasil kreasi dari penyalin inilah yang menunjukkan genius lokalnya.

Aksara Jawi yang dugunakan dan bahasa Minangkabau yang dipakai untuk mengartikan kata teks, juga menggambarkan wacana lokal bagi pembaca atau penyalin naskah saat mempelajari teks. Misalnya, penyalin menggunakan kata menagahkan, bukan memakai kata melarang sebagai kata yang lebih umum bagi masyarakat Indonesia.

Disatukannya naskah teks nahwu, balaghah, dan ilmu mantiq dalam satu naskah, menggambarkan bahwa materi ajar pada pendidikan surau membekali calon ulama dengan ketiga cabang keilmuan tersebut. Bagi masyarakat Minangkabau ketiga ilmu tersebut merupakan modal dalam bertutur khususnya dalam pasambahan, sehingga para alumni surau adalah ulama yang mengerti adat, dan kalau jadi pemangku adat, adalah pemangku adat yang memahami syarak (Islam). Sebagai materi ajar, naskah LBI 03 disusun agar anak didik dapat memfungsikan ilmunya di tengah masyarakat sebagai wahan pengalaman belajar mereka. 


\section{DAFTAR RUJUKAN}

Ansyar, Muhammad. 1989. DasarDasar Pengembangan Kurikulum. Ditjend Dikti-P2LPTK.Jakarta.

Hamka. 2002. Menelusuri Sejarah Minangkabau (Kumpulan Makalah). LKAAM Sumatera Barat. Padang: Citra Budaya.

Helmi, 2006. Luhak Nan Tuo dalam Perspektif Sejarah, Makalah dalam
Kongres Budaya Sumatera Barat di Ina Muara Hotel Padang.

Tjandrasamita, Uka. 2006. KajianNaskah-Naskah Klasik dan Penerapannya Bagi Kajian Sejarah Islam di Indonesia. Jakarta: Puslitbang Lektur Keagamaan Badang Litbang dan Diklat Depag RI.

Zuriati. 2004. Telaah Naskah: Beberapa Aspek dan Seluk-Beluknya. Padang: Fakultas Sastra Universitas Andalas 